\title{
False-Negative RT-PCR Findings and Double Mutant Variant as Factors of an Overwhelming Second Wave of COVID-19 in India: an Emerging Global Health Disaster
}

\author{
Himanshu Jindal ${ }^{1}$ (D) Shubhika Jain ${ }^{2} \cdot$ Tarun Kumar Suvvari $^{3} \cdot$ LVSimhachalam Kutikuppala $^{4} \cdot$ Sudhan Rackimuthu ${ }^{5}$. \\ lan Christopher Naungayan Rocha ${ }^{6} \cdot$ Samarth Goyal ${ }^{2} \cdot$ Radha $^{2}$
}

Accepted: 1 September 2021 / Published online: 21 September 2021

(c) The Author(s), under exclusive licence to Springer Nature Switzerland AG 2021

\begin{abstract}
RT-PCR is considered to be the standard gold diagnostic test for detecting COVID-19 causing SARS-CoV-2. Recent reports and recent pieces of evidence from scientific literature, however, tell a different story. There have been speculations of SARSCoV-2 escaping the RT-PCR because of the series of mutations it has gone through. It is possible that host-dependent RNA editing and high person-to-person transmission have equipped the virus with mutations enabling it to spread faster and even evade the RT-PCR. Added to this is burnout among healthcare workers and technicians handling the RT-PCR machines and sampling. All of these factors may be working in unison to result in the deluge of false-negative cases India is facing during the second COVID-19 wave. The mutant strains are spreading to other parts, posing challenges to the whole world. These circumstances warrant supplementary diagnostic tests such as serological and radiological findings to deal with cases of high clinical suspicion. Even one misdiagnosed COVID-19 patient poses a risk to hundreds of others in the vicinity. Healthcare workers' burnout also has to be dealt with. Erroneous staff should be re-trained.
\end{abstract}

Keywords COVID-19 $\cdot$ Double mutant $\cdot$ Second wave $\cdot$ SARS-CoV-2 $\cdot$ India

\begin{tabular}{|c|c|}
\hline oreviatic & \\
\hline COVID-19 & Coronavirus disease 2019 \\
\hline WHO & World Health Organization \\
\hline SARS-CoV-2 & $\begin{array}{l}\text { Severe acute respiratory syndrome corona- } \\
\text { virus } 2\end{array}$ \\
\hline RT-PCR & $\begin{array}{l}\text { Reverse transcription-polymerase chain } \\
\text { reaction }\end{array}$ \\
\hline
\end{tabular}

Himanshu Jindal

jindalhimanshu.1990@gmail.com

1 Ganesh Shankar Vidyarthi Memorial Medical College, Kanpur, India

2 Kasturba Medical College, Manipal, India

3 Rangaraya Medical College, Kakinada, India

4 Konaseema Institute of Medical Sciences and Research Foundation (KIMS\&RF), Amalapuram, Andhra Pradesh, India

5 Father Muller Medical College, Mangalore, Karnataka, India

6 School of Medicine, Centro Escolar University, Manila, Philippines
CDC
HIV

\begin{abstract}
Centers for Disease Control and
Prevention
\end{abstract}
Human immunodeficiency virus

\section{Introduction}

Almost 6 months after the peak of the first wave of coronavirus disease 2019 (COVID-19) in India in September 2020, the surge in COVID-19 cases started again in the first week of March 2021. As of 28 August 2021, the COVID-19 positive cases summed up to $32,649,947$ and are still counting with daily reported cases soaring to over 40,000 and death toll rising to 437,370 with over 500 deaths per day. Due to the second wave of COVID-19 in India, the test rate was significantly increased to meet the demand, and a total of 516,887,602 samples were tested as of 27 August 2021 [1]. In these unprecedented situations, India is combating the second wave of COVID-19 with an unusual ascent of daily cases.

This unexpected exponential surge of cases can be attributed to the rampant false-negative results of COVID-19 in the country and the newly identified B.1.617, a double 
mutant variant of severe acute respiratory syndrome coronavirus 2 (SARS-CoV-2), which was first detected in India. These, together with increased infection rate, have created a situation of patient overload and increased oxygen demand in hospitals in the country. The WHO has classified all the identified variants of SARS-CoV-2 into two definitive categories - variants of interest (VOI) and variants of concern (VOC). The list of VOCs designated by the WHO includes alpha, beta, gamma, and delta. Currently designated VOIs include eta, lota, kappa, and lambda. As per the WHO's weekly epidemiological update on COVID-19, as of 24 August 2021, the alpha variant has spread to 192 countries, beta to 141 countries, gamma to 86 countries, and delta to 163 countries. All the variants have shown increased transmissibility. In addition, the delta variant has been found to have similar transmissibility between vaccinated and unvaccinated individuals.

\section{Discussion}

\section{Negative RT-PCR and the Second Wave of COVID-19}

Owing to the expeditious transmission of COVID-19 and escalating number of cases, accurate and rapid detection of the virus or the disease is extremely essential for controlling the roots of infection, aiding the patients to prevent further progression, and reducing the severity of disease by creating a window for adequate treatment [2]. This faulty detection of real positive cases seems to be one of the potential causes for the rise in the COVID-19 cases at some places due to the indirect spread of infection from the false-negative persons.

The false-negative outcomes for SARS-CoV-2 from the respiratory samples of the patients are fluctuating between 1 and 30\% [3]. These false-negative results can happen due to various reasons that may include too early or too late testing in the pathogenic process of the virus, suboptimal or poor specimen collection procedures, improper specimen types, scanty analytic sensitivity, negligible viral load, or changeability in the viral shedding. The consequences of these false-negative results could be serious, probably paving a way towards the positive case aggregations leading to negative outcomes and amplified transmission rates across the community [3]. The false-negative results also tend to prevent the person from taking the necessary precautions or treatment required; hence, he/she will be a potential carrier or transmitter of infection in the community, leading to the generation of infected case clusters and hotspots of COVID-19 [4].

\section{Principle and Limitations of RT-PCR}

Real-time reverse transcription-polymerase chain reaction (RT-PCR) is a nuclear-derived method that detects pathogens' genetic material, usually DNA. Since COVID-19 is an RNA virus, RNA is reversely transcripted into DNA using specific enzymes, and obtained DNA is amplified into multiple copies.

The samples from nasopharyngeal or oropharyngeal swabs collected from the patients are kept in specific solutions to eliminate unwanted substances like proteins and fats. The remaining genetic material mixture is placed in an RT-PCR machine. The machine amplifies the DNA into nearly 35 billion copies (from each strand of RNA) by undergoing 35 cycles (standard count). Then, marker labels that are attached to DNA strands release fluorescent dyes. The amount of dye is measured by a computer and displayed on the screen using real-time. The amount of dye in the sample is tracked after each cycle, and if the amount of fluorescent dye reaches a certain level, the presence of the virus can be confirmed. The number of cycles it takes to reach that certain level determines the severity of infection. A low number of cycles indicates severe infection $[5,6]$.

According to the Centers for Disease Control and Prevention (CDC), the negative results do not interdict COVID-19 infection, and collection of multiple specimens is recommended. Similarly, the presence of viral RNA may not be a confirmatory indication for clinical symptoms developed in a patient. False-positive and false-negative results highly depend on the prevalence of disease in the human body. The higher the prevalence of disease, the more chances of falsenegative results, and vice-versa. Regarding the reliability of the test for detection of COVID-19, RT-PCR is considered the standard gold test due to its high specificity and significant sensitivity [2]. However, few authors have reported that the sensitivity of RT-PCR could be as low as $38 \%$, almost like a chance. IgM and IgG serology tests have been reported across the globe and under being used, but the specificity and sensitivity of serology tests is also not high [7].

\section{Mutations and Associated False-Negative Results}

The release of the first SARS-CoV-2 genome sequence occurred on 10 January 2020, which paved the way for developing complementary RT-PCR assays [8]. However, due to high transmission cycles, the virus may have mutated, posing a threat to the sensitivity of RT-PCR as the reagents for the kits were also developed then.

The SARS-CoV-2 is an enveloped ssRNA virus, which generally tends to have very high mutation rates. However, human coronaviruses have an RNA polymerase with $3^{\prime}$ to $5^{\prime}$ proofreading activity that allows them to replicate 
with "high-fidelity" and thus, its mutation rate is moderate [8-10]. The mutation rate of SARS-CoV-2 is $\sim 2$ nucleotides per month in contrast to that of influenza (4 nucleotides per month) or HIV (8 nucleotides per month) [11]. However, host-dependent RNA editing [9] and high rate of personto-person transmissibility $[8,12]$ cannot be left out of the picture.

Physicians closely studying the second wave in India have claimed that bronchoalveolar lavage performed on RT-PCR negative patients presenting with definitive symptoms of COVID-19 yielded COVID-19 positive results. A doctor in the same report said that approximately 15 to $20 \%$ of COVID-19 patients are presenting with the above condition, and it is becoming a dilemma for the physicians [13]. In another report, a scientist argued that mutations in the SARS-CoV-2 may have made it capable of evading RTPCR testing and that there is a need to re-configure the kits urgently [14]. There are reports where chest computed tomography (CT) findings are clearly indicative of COVID19 (ground-glass opacity and grey patches), but repeated RTPCR tests have yielded negative results. Although it is being speculated that since RT-PCR has a sensitivity of $70 \%$, it is the remaining portion of patients that are getting false-negative results [13-17]. However, these reports have surfaced only recently, so the possibility of mutant(s) of SARS-CoV-2 causing this cannot be neglected completely. According to a news report, the data shared by the National Institute of Virology, India, almost $61 \%$ of the samples collected from the Indian state of Maharashtra were positive for the presence of the double mutant strain B.1.617 [18]. The Global Times reported that eleven Chinese crew members became positive with a mutant Indian strain of the SARS-CoV-2 [19].

Several studies have hinted out that the inevitable genetic evolution and mutation of SARS-CoV-2 can compromise the sensitivity of RT-PCR diagnostic kits [8, 10-12, 20-23]. The diagnostic assays used in RT-PCR have high specificity, due to which even a few mutations can lead to substantial loss of sensitivity [23]. Most of the mutations of SARSCoV-2 occur on the Nucleocapsid (N) gene target, primers, and probes of which are extensively used around the world for the detection of this virus [21].

Various recent literature and scientific evidence support the rationale of mutations leading to increased false-negative RT-PCR results for SARS-CoV-2. A study found that an SNP (Single Nucleotide Polymorphism) in the N gene interfered with the detection through commercial diagnostic assays in a SARS-CoV-2 positive patient [23]. An analysis in a study also showed that there were mutations/mismatches in primer/probe binding regions of 7 out of 27 assays that were studied [10]. Another study detected the presence of a mutation in the $\mathrm{N}$ gene of SARS-CoV-2 in 3 patients, which affected its detection by commercial assays [12]. Reports claim that single mutation in forward $\mathrm{N}$ gene primer binding site, prevalent across the world, decreased the RT-PCR sensitivity for SARS-CoV-2 [22]. A study that had genotyped 31,421 SARS-CoV-2 genome isolates has also revealed that per se, "all of the current COVID-19 diagnostic targets have undergone mutations" [24]. Another study that investigated the impact of Intra-host Single Nucleotide Variants (iSNVs) and Single Nucleotide Polymorphisms (SNPs) on the probes and primers commonly used in RT-PCR found that most of the probes had iSNVs and SNPs [9]. Although this did not affect target hybridization in the study, our rationale is that mutations like these could increase the chances of falsenegative results being obtained upon RT-PCR.

If the mutational profile and data could be integrated into developing PCR arrays, higher sensitivity for primer and probe hybridization could be achieved [9]. This also implies that having multiple gene targets in RT-PCR could vastly reduce the risk of loss of sensitivity due to the inevitable mutations in the virus $[15,16,18,20]$.

\section{Collapsing Healthcare and Rampant False-Negative Results}

The weakening of a country's healthcare system, its management, and the available medical infrastructure have been the most important contributing facets to the increasing morbidity and mortality due to COVID-19. The recent deterioration of the healthcare sector has further amplified false-negative RT-PCR results, and as a result has led to a rise in misdiagnoses, causing an increased risk of infection transmission. The fundamental cause for the false-negative test results among the COVID-19 patients during these times can be attributed much to the erroneous lab personnel who are having an acutely aggravated workload amidst the second wave. Collapsing healthcare and false-negative RT-PCR results are, therefore, now a part of a vicious cycle further fueling one another. False-negative RT-PCR results have been attributed to several pre-analytical, analytical, and post-analytical causes [25].

RT-PCR being extensively employed for mass testing has led to a scarcity of skilled personnel as well as snowballing rates of healthcare workforce burnout which include physicians and medical technicians among many others [26, 27]. As a result of the amalgamation of increased workload, risk of transmission, and shortage of necessary resources, the physical and mental health of healthcare workers has been severely affected [28]. Physicians' and healthcare workers' feeling of exhaustion may also be further accentuated in the future due to the growing backlog of healthcare services and procedures, which must also be given due consideration.

An immediate outcome of shortage of skilled personnel and burnout may include an improper collection of specimens giving rise to insufficient viral load required 
for detection, improper transportation, improper handling of samples, inefficient extraction of RNA, and the inept removal of amplification inhibitors from the specimens [2, 29-31]. The above factors may also be influenced by the lack of equipment, material, bio-safety labeling, and instrumentation required for effective RT-PCR testing due to overburdened healthcare. The viral load in the specimen being fluctuant during the progression of the disease continues to perplex the timing of specimen collection, further contributing to false-negative results $[31,32]$.

As the SARS-CoV-2 RT-PCR is increasingly being applied to the asymptomatic population, avoidable repeat testing is becoming more prevalent. This consistently strains the supply chain network causing a delay in the turnaround time for the results, and more crucially leading to a paucity of tests for those who may need testing the most [33]. The multiplying demand has placed undue pressure on the principal manufacturing units causing disruption of overall logistics, leading to failure of delivery of the material required for diagnostic testing to the general population. [34].

\section{Action Plan and Recommendations}

RNA-based viruses change variants frequently and COVID19 is no exception. To tackle this, genomic sequencing capacities should be ramped up so as to facilitate surveillance of emerging variants. Also, the limitations that exist in sampling strategies worldwide should be reduced. It is also possible that while the diagnostic kits do not change much over time, the virus is undergoing a myriad of mutations which may also give rise to variants/mutants that can evade the RT-PCR or at least substantially affect its sensitivity. There is a need to constantly watch out for such mutants/variants. Along with that, supplementary diagnostic tests like chest high-resolution CT scan and inflammatory markers (CRP, D-dimer, LDH, ferritin, IL-6) should be considered of great diagnostic value in a case of high clinical suspicion with a negative RT-PCR test report.

If the patient has clinical symptoms of COVID-19 and tests negative in RT-PCR, then multiple nasal and pharyngeal swabs at different times should be tested. Laboratory data, clinical symptoms, and CT images should be altogether considered to confirm the viral infection. The irrational results in RT-PCR can be minimized by following reasonable sampling procedures, standard laboratories, and premium quality RT-PCR kits [2]. Though RT-PCR is based on conserved sequences, primers in different genes can be affected by variations of viral RNA sequences.

\section{Conclusion}

The growing menace of increasing false-negative results in SARS-CoV-2 RT-PCR should be dealt with urgently. Even one falsely negative patient could put at risk the lives of hundreds of people in the vicinity. Additionally, the presence of double mutant B.1.617 variant is also a potential contributing factor to the exponential surge of COVID-19 cases in India as it has shown to be transmissible similarly in vaccinated and unvaccinated individuals. The B.1.617.2 (double mutant variant, delta variant) has been classified as a variant of concern. These factors are hampering the efforts of governments all over the world to contain the spread of COVID-19.

Changes in the viral nucleic acid and protein sequences put at risk the utility of certain in vitro diagnostic assays if the mutation occurs in an area critical for primer or antibody binding in RT-PCR and immunoassays. As the new variants of the SARS-CoV-2, including B.1.617, arise, it is the need of the hour that the PCR and diagnostic assays be re-configured and optimized. Multiple gene targets should be identified, and PCR assays should be reconfigured to use them. Extensive research/clinical trials should be sought in this direction. Data for the genome of the mutant variants of the virus should be readily available and infection prevention and control (IPC) measures as well as public health and social measures (PHSM) should change accordingly so as to accommodate additional preventive measures against the variants.

In addition, healthcare workers' burnout has to be looked at. Provisions should be made to recruit additional technical staff for handling various equipment and train them simultaneously. A possible reason for the high rate of false-negative RT-PCR results is improperly trained personnel who fail to take samples appropriately and lack basic training. Such staff should be re-trained.

Author Contribution Himanshu Jindal and Shubhika Jain conceived the idea and design, wrote the abstract, introduction, and discussion, organized the list of references, and edited the final draft; Tarun Kumar Suvvari and LV Simhachalam Kutikuppala wrote the introduction and discussion; Sudhan Rackimuthu and Radha wrote the discussion and conclusion; Samarth Goyal wrote the discussion and did the final revision; Ian Christopher Naungayan Rocha and Shubhika Jain made critical comments and revision. All authors revised and approved the final manuscript. 


\section{Declarations}

Ethics Approval and Consent to Participate Not applicable.

Consent for Publication All authors agreed to publish this manuscript.

Conflict of Interest The authors declare no competing interests.

\section{References}

1. \#IndiaFightsCorona COVID-19 in India, vaccination, dashboard , corona virus tracker I mygov.in. Accessed 29 Aug 2021. https:// www.mygov.in/covid-19/

2. Tahamtan A, Ardebili A. Real-time RT-PCR in COVID-19 detection: Issues affecting the results. Expert Rev Mol Diagn. 2020;20(5):453-4. https://doi.org/10.1080/14737159.2020.17574 37.

3. Kanji JN, Zelyas N, MacDonald C, et al. False negative rate of COVID-19 PCR testing: A discordant testing analysis. Virol J. 2021;18(1):13. https://doi.org/10.1186/s12985-021-01489-0.

4. www.ETHealthworld.com. COVID-19: False negatives on test raise questions about accuracy - ET HealthWorld. ETHealthworld. com. Accessed 30 Apr 2021. https://health.economictimes.india times.com/news/diagnostics/covid-19-false-negatives-on-testraise-questions-about-accuracy/75734308

5. Taking connected mobile-health diagnostics of infectious diseases to the field I Nature. Accessed 1 May 2021. https://www.nature. com/articles/s41586-019-0956-2

6. How is the COVID-19 virus detected using real time RT-PCR? Published March 27, 2020. Accessed 1 May 2021. https://www. iaea.org/newscenter/news/how-is-the-covid-19-virus-detec ted-using-real-time-rt-pcr

7. Dramé M, Teguo MT, Proye E, et al. Should RT-PCR be considered a gold standard in the diagnosis of Covid-19? J Med Virol. 2020. https://doi.org/10.1002/jmv.25996.

8. Artesi M, Bontems S, Göbbels P, et al. A recurrent mutation at position 26340 of SARS-CoV-2 is associated with failure of the E gene quantitative reverse transcription-PCR utilized in a commercial dual-target diagnostic assay. Caliendo AM, ed. J Clin Microbiol. 2020;58(10):e01598-20, https://doi.org/10.1128/JCM.01598-20

9. Sapoval N, Mahmoud M, Jochum MD, et al. SARS-CoV-2 genomic diversity and the implications for qRT-PCR diagnostics and transmission. Genomic Divers. 11.

10. Khan KA, Cheung P. Presence of mismatches between diagnostic PCR assays and coronavirus SARS-CoV-2 genome. : 17.

11. Ascoli CA. Could mutations of SARS-CoV-2 suppress diagnostic detection? Nat Biotechnol. 2021;39:274-75. https://doi.org/10. 1038/s41587-021-00845-3.

12. Hasan MR, Sundararaju S, Manickam C, et al. A novel point mutation in the $\mathrm{N}$ gene of SARS-CoV-2 may affect the detection of the virus by reverse transcription- quantitative PCR. J Clin Microbiol. 2021;59(4):3.

13. Covid-19: Stealthy virus beating RT-PCR tests, find doctors; here's how they're finding ways to treat patients. Accessed $26 \mathrm{Apr}$ 2021. https://www.timesnownews.com/health/article/covid-19stealthy-virus-beating-rt-pcr-tests-find-doctors-heres-how-docto rs-are-finding-the-way/744614

14. CT-scan confirms infection for several RT-PCR negative reports I Indore News - Times of India. The Times of India. Accessed 26 Apr 2021. https://timesofindia.indiatimes.com/city/indore/ct-scanconfirms-infection-for-several-rt-pcr-negative-reports/articleshow/ $82128536 . \mathrm{cms}$
15. Coronavirus variant causing second wave, highly stealthy beats RT-PCR tests, say doctors. Published April 13, 2021. Accessed 26 Apr 2021. https://www.news18.com/news/india/coronavirusvariant-causing-second-wave-highly-stealthy-beats-rt-pcr-testssay-doctors-3634499.html

16. False Covid negatives force repeat RT-PCR tests I Kolkata News - Times of India. The Times of India. Accessed 26 Apr 2021. https://timesofindia.indiatimes.com/city/kolkata/false-covid-negat ives-force-repeat-rt-pcr-tests/articleshow/82027764.cms

17. New Covid symptoms: Stealthy virus beating RT-PCR tests, find docs I India News - Times of India. The Times of India. Accessed 26 Apr 2021. https://timesofindia.indiatimes.com/india/covid-19stealthy-virus-beating-rt-pcr-tests-find-docs/articleshow/82040 394.cms

18. Explained: B.1.617 variant and the Covid-19 surge in India I Explained News, The Indian Express. Accessed 4 May 2021. https://indianexpress.com/article/explained/maharashtra-doublemutant-found-b-1-617-variant-and-the-surge-7274080/

19. Chinese cities detect COVID-19 mutant strains found in India Global Times. Accessed 4 May 2021. https://www.globaltimes. $\mathrm{cn} /$ page/202104/1222517.shtml?fbclid=IwAR0E8f1iupCRnTTt3a Dc5rif5CTBpeKY41jaX-4M2gdnzq8OjqpuS9E-Ww0

20. Pearrubia L. Multiple assays in a real-time RT-PCR SARS-CoV-2 panel can mitigate the risk of loss of sensitivity by new genomic variants during the COVID-19 outbreak. International Journal of Infectious Diseases. Published online 2020:5.

21. Lee $\mathrm{S}$. Novel indel mutation in the $\mathrm{N}$ gene of SARS-CoV-2 clinical samples that were diagnosed positive in a commercial RT-PCR assay. Virus Research. Published online 2021:4.

22. Vanaerschot M, Mann SA, Webber JT, et al. Identification of a polymorphism in the $\mathrm{N}$ gene of SARS-CoV-2 that adversely impacts detection by reverse transcription-PCR. J Clin Microbiol. 2021;59(1):4.

23. Ziegler K, Steininger P, Ziegler R, Steinmann J, Korn K, Ensser A. SARS-CoV-2 samples may escape detection because of a single point mutation in the $\mathrm{N}$ gene. Euro Surveill. 2020;25(39):pii=2001650. https://doi.org/10.2807/1560-7917. ES.2020.25.39.2001650.

24. Wang R, Hozumi Y, Yin C, Wei G-W. Mutations on COVID-19 diagnostic targets. Genomics. 2020;112(6):5204-13. https://doi. org/10.1016/j.ygeno.2020.09.028.

25. Preanalytical issues affecting the diagnosis of COVID-19| Journal of Clinical Pathology. Accessed 1 May 2021. https://jcp.bmj.com/ content/74/4/207.abstract

26. Roslan NS, Yusoff MSB, Asrenee AR, Morgan K. Burnout prevalence and its associated factors among Malaysian healthcare workers during COVID-19 pandemic: An embedded mixed-method study. Healthcare. 2021;9(1):90. https://doi.org/10.3390/healt hcare9010090.

27. Burnout among healthcare workers during COVID-19 pandemic in India: Results of a questionnaire-based survey. Accessed 1 May 2021. https://www.ncbi.nlm.nih.gov/pmc/articles/PMC7519601/

28. Impact of coronavirus disease 2019 on healthcare workers: Beyond the risk of exposure I Postgraduate Medical Journal. Accessed 1 May 2021. https://pmj.bmj.com/content/early/2020/ 06/18/postgradmedj-2020-137988.abstract

29. Joob B, Wiwanitkit V. SARS-CoV-2 RT-PCR test, false result problem, public risk assessment and reliability of epidemiology statistics. J Taibah Univ Med Sci. 2020;16(1):136-7. https://doi. org/10.1016/j.jtumed.2020.10.012.

30. Mo X, Qin W, Fu Q, Guan M. Understanding the influence factors in viral nucleic acid test of 2019 novel coronavirus (2019-nCoV). Chin J Lab Med. 2020;43(00):E002-E002. https://doi.org/10. 3760/cma.j.issn.1009-8158.2020.0002.

31. Feng W, Newbigging AM, Le C, et al. Molecular diagnosis of COVID-19: Challenges and research needs. Anal Chem. 
2020;92(15):10196-209. https://doi.org/10.1021/acs.analchem. 0c02060.

32. Charting the challenges behind the testing of COVID-19 in developing countries: Nepal as a case study - ScienceDirect. Accessed 1 May 2021. https://www.sciencedirect.com/science/article/pii/ S2590053620300471?via\%3Dihub

33. Challenges and controversies to testing for COVID-19| Journal of Clinical Microbiology. Accessed 1 May 2021. https://jcm.asm. org/content/58/11/e01695-20.abstract
34. Vandenberg O, Martiny D, Rochas O, van Belkum A, Kozlakidis Z. Considerations for diagnostic COVID-19 tests. Nat Rev Microbiol. 2021;19(3):171-83. https://doi.org/10.1038/ s41579-020-00461-Z.

Publisher's Note Springer Nature remains neutral with regard to jurisdictional claims in published maps and institutional affiliations. 